\title{
Spillover Effects of Trade Shocks in the Central and Eastem European and Baltic Countries
}

\author{
Nazmus Sadat Khan ${ }^{1,2+}$ \\ ${ }^{1}$ The World Bank, Dhaka, Bangladesh \\ ${ }^{2}$ University of Muenster, Muenster, Germany
}

\begin{abstract}
How does a trade shock occurring in each Central and Eastern European and Baltic country affect the economic growth and inflation of other CEE-Baltic countries? This paper addresses this question by comparing the spillover effects of trade shocks using a global vector auto-regression model with 10 CEE-Baltic countries. In constructing the foreign variables, a time-varying trade weight is used instead of a fixed weight. Oil price is included as a global variable because of its importance to the countries in the region. The results demonstrate that the trade spillover effects are strong in the region and have a positive impact on economic growth and inflation in the region. However, the Czech Republic, Slovakia, and Poland play a greater role in this transmission process than the other countries.
\end{abstract}

Keywords: Trade, Spillover Effects, Global Vector Auto-Regression, Central and Eastern European and Baltic Countries.

\section{Introduction}

The Central and Eastern European and Baltic (CEE-Baltic) countries have experienced several economic transformations over recent years. After the fall of the Berlin Wall, a number of these former Soviet states faced an incomplete process of integration without any clear economic or foreign policy attachments. As they began the process of transforming their economies from what was previously known as a centrally planned economy to a market-oriented economy, integration with the eurozone began to increase. The institutional, social, and economic reforms that these countries experienced over the last two decades helped them grow rapidly and become more interconnected. Geographical proximity, improved business environment, and several

\footnotetext{
+Corresponding Author: Nazmus Sadat Khan

Economist, The World Bank, plot E-32, Agargaon, Sher-E-Bangla Nagar, Dhaka, Bangladesh, Tel: +88 01729236599 , E-mail: nkhan12@worldbank.org
}

Acknowledgements: This research was conducted at the Oxford School of Global and Area Studies at the University of Oxford with the generous support of the Fritz Thyssen Institute. I am grateful to Prof. Chris Gerry of the University of Oxford for his valuable comments. The views and interpretations are those of the author and do not represent those of the World Bank and its Executive Directors, nor the countries that they represent. 
agreements led to reduced barriers in labor mobility and significantly helped reduce the trade barriers. The advantages offered by globalization and the development of information technology (IT) helped these countries achieve significant improvement in their standards of living. Almost all these countries are now members of the European Union (EU) and the North Atlantic Treaty Organization (NATO). Slovakia, Slovenia, Estonia, Latvia, and Lithuania even adopted the euro as their single currency. As a result, both trade links and financial ties have intensified between these countries (Mann 2015). Although these links have promoted the growth of the CEE-Baltic states, these countries have also become more vulnerable to external negative shocks. This was evident during the global financial crisis of 2007-2008 and the subsequent sovereign debt crisis in the eurozone.

A significant increase in trade volume within the CEE-Baltic countries has occurred over the last decade. Therefore, it is expected that changes in trade volume in one country are likely to affect neighboring countries. As these countries become more interconnected, it now becomes important to understand their level of interdependence. That is, how does a change in a certain macroeconomic variable (particularly in trade) of one country affect the economies of other countries? This question has not yet been properly investigated in the existing academic literature regarding CEE-Baltic countries. Learning more about these spillover effects of trade shocks within the region will help policymakers better prepare for trade negotiations and more efficiently implement policies that will have the best effect on their individual countries.

This paper uses a global vector auto-regressive (GVAR) method to investigate the impact of trade shocks of one CEE-Baltic country on other CEE-Baltic countries using quarterly data for the period between the first quarter of 2003 (2003Q1) and the fourth quarter of (2017Q4). It makes two primary contributions to the literature. Firstly, this study focuses on the spillover effects of trade shocks solely within the CEE-Baltic region. Previous studies (Awokuse 2007, Iyke 2017, Nannicini and Billmeier 2011, Wacziarg and Welch 2008) have focused on the effect of trade openness on economic growth in the context of CEE-Baltic countries and found some evidence that trade has a positive impact on these economies. However, these studies concentrated on a single country or a group of countries, and countries were not modeled for effects on each other. In other words, none of these scholars analyzed the spillover effects from one country to another. This paper fills this gap by investigating the spillover effects of trade on economic growth and inflation within the CEE-Baltic region.

Secondly, this study uses GVAR analysis, a novel econometric approach proposed by Pesaran et al. (2004). Having a large number of countries and variables in the model is technically challenging because there are potentially many more variables and parameters than observations. Compared with factor-augmented VAR (FAVAR) models, which are also used in multicountry spillover analysis, the GVAR approach can combine the different macroeconomic variables of a large number of countries in a consistent and convenient manner. 
Here, individual country models are added by means of a consistent econometric approach to arrive at a global model in which co-integration is allowed for variables within and across countries. FAVAR models capture country-specific dynamics only through idiosyncratic components (e.g., the residuals). Moreover, in FAVAR models, variables are often rendered stationary via differencing. In GVAR models, data can be used in levels, thus retaining the information's long-run data. In two previous papers, Hajek and Horvath (2016) and Feldkircher (2015) used GVAR models for CEE countries. They considered all the CEE-Baltic countries as a group and investigated how shocks from the EU and the rest of the world affected them. They did not explicitly study the effect on individual CEE-Baltic countries in which the shocks originated. Trade was also not a main focus of these papers. Rather than the commonly used fixed trade weight characteristic of GVAR literature, this study uses a time-varied trade weight to construct the foreign variables in each country's model. This helps account for the evolving nature of trade relationships between these countries over the sample period.

The results of this study will enable a better understanding of the trade and economic interconnections among CEE-Baltic countries. This, in turn, will have important implications for economic and political decision making for all the countries in the region. This paper is organized as follows: Section 2 discusses the literature; the GVAR model is described in Section 3; Section 4 describes the data and some important statistical properties of the GVAR model; Section 5 discusses some initial results and the results of impulse response analysis; some robustness checks are conducted in Section 6; and, finally, Section 7 concludes.

\section{Literature Review}

Although there is a growing literature regarding the spillover effects within the major EU countries and between developed and emerging economies, studies focusing on the CEE-Baltic countries remain limited, mainly due to a lack of sufficiently long macroeconomic time series data. With the recent increase in data availability, these topics now deserve more comprehensive analysis. The few studies that analyze spillover effects concentrate on the effects experienced by Western European countries from Eastern European countries through capital and financial markets (Backe and Slacik 2013, Harrison and Moore 2009, Serwa and Bohl 2005, Syllignakis and Kouretas 2011). Some papers discuss the effect of the European Central Bank's (ECB) monetary policy on non-eurozone members of the EU (Benkovskis et al. 2011, Horvath and Rusnak 2009, Kucharcukova et al. 2016). Studies that focus on other variables are scarce. Among them, Jimenez-Rodriguez et al. (2010) used a near-VAR model with macroeconomic data consisting of interest rates, industrial production, and commodity prices for the eurozone, the United States (US), and 10 CEE countries. The results show that a positive shock in foreign 
economies such as the US and the eurozone results in a reduction in industrial production and commodity prices in CEE countries. Hajek and Horvath (2016) analyzed similar variables and found that the response of CEE countries to eurozone shocks is almost as strong as the responses of the eurozone countries themselves. Mackowiak (2006) investigated the sources of variation in real aggregate outputs and aggregate price levels in the Czech Republic, Hungary, and Poland. He found that German macroeconomic variables have a significant effect on the domestic variables of these countries. Keppel and Prettner (2015) used a generalized impulse response analysis to investigate the interrelation between the eurozone and five CEE countries (the Czech Republic, Hungary, Poland, Slovenia, and Slovakia). The results showed that a positive shock in the eurozone gross domestic product (GDP) had a positive effect on the GDP of CEE countries. Feldkircher (2015) constructed a global macroeconomic model for 43 countries, including the CEE countries, and checked the effect of output, interest rate, and oil price shocks. The model showed that the CEE output reacts nearly equally as strongly to a US-originated output shock as it does to a corresponding shock in the eurozone.

\section{GVAR Model}

The GVAR approach, introduced by Pesaran et al. (2004), provides a relatively simple yet effective way of modeling today's global economy, in which each country and the different macroeconomic factors within the countries are related to each other. The GVAR methodology of modeling comprises two distinct stages. In the first step, a separate VARX model is estimated for each individual country. If some of the variables have unit roots and are co-integrated, the model is estimated in its error-corrected form. In these individual VARX (or VECMX) models, each country is described according to three different types of variables: domestic, foreign, and global. Domestic variables are endogenous to the model, whereas foreign and global variables are exogenous. Each domestic variable has corresponding foreign variables. These foreign variables are constructed using a weight matrix so that the relative importance of different countries is reflected properly. They provide a connection between the evolution of the domestic economy and the rest of the world. These foreign variables are considered to be weakly exogenous, which is an assumption that needs to be tested. Global variables are included in each country model as exogenous variables, and they are identical for all countries. In the second step, these individual VARX (or VECMX) models are combined in a consistent manner with the help of a link matrix to build a global model. 


\section{A. Individual country model}

Let there be $N+1$ countries in the model, indexed by $i=0,1,2, \cdots, N$, where country 0 is considered the reference country. Each country $i$ then follows the $\operatorname{VARX}(p, q)$ model:

$$
y_{i, t}=a_{i, 0}+a_{i, 1} t+\sum_{j=1}^{p} a_{i, j} y_{i, t-j}+\sum_{j=1}^{q} \beta_{i, j} y_{i, t-j}^{*}+a_{i, 2} d_{t}+u_{i, t}
$$

for $t=0,1,2, \ldots, T$. Here, the $k_{i} \times 1$ matrix $y_{i, t}$ represents the endogenous domestic variables and the $k_{i}^{*} \times 1$ matrix $y_{i, t}^{*}$ represents the corresponding (weakly) exogenous foreign variables. $k$ and $k^{*}$ are the numbers of domestic and foreign variables, respectively, $a_{i, 0}$ is a $k_{i}^{*} \times 1$ vector of fixed intercepts, and $a_{i, 1}$ is a $k_{i}^{*} \times 1$ vector of coefficients on the deterministic time trends. $p$ and $q$ denote the lag lengths of the domestic and foreign variables, respectively. They are selected according to the Schwartz Bayesian (SB) criterion. $d_{t}$ is a set of global variables and $a_{i, 2}$ is a vector of their respective coefficients. Finally, $u_{i, t} \sim \operatorname{iid}\left(0, \sum u_{i}\right)$.

Foreign variables are calculated as the weighted average of the rest of the countries' value for that variable. More specifically:

$$
y_{i, t-j}^{*}=\sum_{j=1}^{N} \omega_{i, j, t} y_{j, t}
$$

where $\omega_{i, j, t}$ is a weighting factor that captures the importance of country $j$ for country $i$, with $\sum_{j=1}^{N} \omega_{i, j, t}=1$ and $\omega_{i, i, t}=0$. Most of the GVAR literature uses fixed trade weights based on bilateral trade volumes. However, these may be subject to temporal changes, particularly for the time period considered in this paper because it includes the 2007 2008 period of financial crisis and years during which some of the CEE countries joined the eurozone. As a result, using a fixed weight might misinterpret the results. To take account of these changes that occurred during the sample period, this paper uses time-varying weights to construct the foreign variables in the country-specific models. These are constructed as three-year moving averages to smooth out short-run business cycle effects in bilateral trade flows.

More compactly, setting $p_{i}=\max (p, q)$, Equation 1 can be written as:

$$
A_{i, 0} z_{i, t}=a_{i, 0}+a_{i, 1} t+\sum_{j=1}^{p_{i}} a_{i, j} y_{i, t-j}+\sum_{j=1}^{q} A_{i, j} z_{i, t-j}+u_{i, t}
$$

where vector $z_{i, t}=\left(x_{i, t}^{\prime}, x_{i, t}^{*}\right)^{\prime}$ represents both domestic and foreign variables and the coefficient matrices are $A_{i, 0}=\left(I_{k, i},-\beta_{i, 0}\right)$ and $A_{i, j}=\left(\alpha_{i, j}, \beta_{i, j}\right)$.

Because of the characteristics of the macroeconomic variables and to allow the co-integrating 
relationship within and between countries, the country-specific VARX models are estimated using the following error-corrected form (VECMX):

$$
\triangle y_{i, t}=c_{i, 0}+a_{i} \beta_{i}^{\prime}\left(z_{i, t-1}-a_{1, t}(t-1)+\beta_{i, 0} \Delta y_{i, t}^{*}+\sum_{j=1}^{p_{i-1}} \phi_{i, j} \Delta z_{i, t-j}+u_{i, t}\right.
$$

Here, $a_{i}$ is a $k_{i} \times r_{i}$ matrix of rank $r_{i}$ and $\beta_{i}$ is a $\left(k_{i}+k_{i}^{*}\right) \times r_{i}$ matrix of rank $r_{i}$. The country-specific VECMX models are estimated using reduced rank regression conditionals on weakly exogenous foreign variables. This takes into account the possibility of co-integration within domestic variables and across domestic and foreign variables. Using this method, estimates for $r_{i}, \beta_{i}$, and $\alpha_{i}$ are obtained. The other parameters are estimated by ordinary least squares (OLS) using this Equation 5:

$$
\triangle y_{i, t}=c_{i, 0}+\delta E C M_{i, t-1}+\beta_{i, 0} \Delta y_{i, t}^{*}+\phi_{i} \Delta z_{i, t-j}+u_{i, t}
$$

where $E C M_{i, t-1}$ is the error correction term referring to the $r_{i}$ co-integrated relations of the $i$ th country model.

\section{B. Global model}

The next step is to combine the individual country-specific parameter estimates into a single global model. All the country-specific variables are considered as a single $k \times 1$ global vector $y_{t}=\left(y_{0 t}^{\prime}, y_{01}^{\prime}, \cdots, y_{N t}^{\prime}\right)^{\prime}$ where $k=\sum_{i=0}^{N} k_{i}$, so that all the variables are endogenous in the system as a whole. For each country, the corresponding VARX model is obtained from the VECMX model that was estimated. The link matrix $W_{i}$, which is the $\left(k_{i}+k_{i}^{*}\right) \times k$ matrix collecting the trade weights $\omega_{i j}, \forall i, j=0,1,2, \cdots, N$, is used to obtain the identity $z_{i, t}=W_{i} y_{t}$.

From Equation 3, it follows that:

$$
A_{i, 0} W_{i} y_{t}=a_{i, 0}+a_{i, 1} t+\sum_{j=1}^{p_{i}} A_{i, j} W_{i} y_{t-j}+u_{i, t}
$$

for $i=0,1, \cdots, N$. The $N+1$ systems in Equation 6 are then combined to calculate the global model in levels:

$$
G_{0} y_{t}=a_{0}+a_{1} t+\sum_{i=1}^{p} G_{i} y_{t-i}+u_{t}
$$

Here, $G_{0}=\left(A_{00} W_{0}, A_{10} W_{1}, \cdots, A_{N 0} W_{N}\right)^{\prime}$ is a known nonsingular $k \times k$ matrix that depends 
on the trade weights and parameter estimates $G_{i}=\left(A_{0 i} W_{0}, A_{1 i} W_{0}, \cdots, A_{N i} W_{N}\right)^{\prime}$ for $i=0,1, \cdots, p$, $a_{0}=\left(a_{00}, a_{10}, \cdots, a_{N 0}\right)^{\prime}, a_{1}=\left(a_{01}, a_{11}, \cdots, a_{N 1}\right)^{\prime}, u_{t}=\left(u_{0 t}, u_{1 t}, \cdots, u_{N t}\right)$ and $p=\max \left(p_{i}\right)$, across all $i$. Premultiplying Equation 7 by $G_{0}^{-1}$, the $\operatorname{GVAR}(\mathrm{p})$ model obtained is:

$$
y_{t}=b_{0}+b_{1} t+\sum_{i=1}^{p} F_{i} y_{t-i}+\varepsilon_{t}
$$

where $b_{0}=G_{0}^{-1} a_{0}, b_{1}=G_{0}^{-1} a_{1}, F_{i}=G_{0}^{-1} G_{i}$ for $i=0,1, \cdots, p$, and $\varepsilon_{t}=G_{0}^{-1} u_{t}$. The dynamic properties of the GVAR model in Equation 8 can be examined using generalized impulse response functions (GIRFs).

\section{Data and Some Relevant Tests}

This section describes the data, some test results important for the GVAR model to hold, and the contemporaneous effects that provide initial information about the levels of integration of the different countries and the time-varying weights.

\section{A. Data}

The GVAR model consists of 10 CEE-Baltic countries: Bulgaria, Croatia, the Czech Republic, Hungary, Poland, Romania, Slovakia, Slovenia, Estonia, and Latvia. Other smaller CEE-Baltic countries were left out due to the unavailability of their data for longer periods. In addition to GDP growth (Growth) and total trade (Trade), three other variables are used in each country model: consumer price index (CPI) to control for prices, short-term interest rate (SIRT) to control for monetary policy, and real effective exchange rate (REER). ${ }^{1)}$ These variables are generally associated with the transmission mechanism of trade shocks and can be vulnerable to foreign variables.2) Growth and inflation are the two variables that have remained subdued in eurozone countries since the financial crisis. Therefore, when considering further integration among countries, how these two variables react to foreign shocks will be of particular interest to policymakers. Quarterly data are used between 2003Q1 and 2017Q4.

As the main objective of this study is to investigate the spillover effects of trade shocks, it is important to define this variable correctly. Here, trade data in individual country models represent the sum of that country's exports and imports with other countries in the model. A number of observers focus on the value of the trade balance (the difference between exports

1) Except for Latvia, for which short-term interest rate data were unavailable.

2) See Cakir and Kbundi (2013) and Andrews and Rees (2009). 
and imports) and its effect, instead of total trade (the sum of exports and imports). ${ }^{3)}$ The trade balance, however, can be a poor indicator of overall economic prosperity in the region. Trade, whether exports or imports, allows each nation to concentrate its labor, capital, and resources on the economic pursuits at which it is most productive relative to other countries. This helps generate greater output in the region, which is shared by its participants, even though the effect on trade balances might be negative in some countries. Further, because the aim is to see the effect within CEE-Baltic countries, only trade with other CEE-Baltic countries is considered-not overall trade with the rest of the world. This helps separate the effects due to trade within CEE-Baltic countries from trade with the rest of the world. The importance of oil prices in the transmission mechanism of these variables has been well recognized in the literature (Taghizadeh-Hesary et al. 2013, 2016, Taghizadeh-Hesary and Yoshino 2018). This is particularly important for CEE-Baltic countries as their economies are strongly influenced by oil prices. Therefore, oil price (as an average of West Texas Intermediate (WTI) and Brent crude) has been used in the model as a global variable. This is in li ne with the other GVAR models.

As most of the countries in the sample have their own currencies, measuring and using the data for trade in different currencies can often lead to misleading results. Therefore, for ease of comparison, the data for these variables are taken from the International Monetary Fund's (IMF's) "Direction of Trade Statistics (DOTS)," which converts them into a common currency (the US dollar). For each country, the values of bilateral export and import with the rest of the CEE-Baltic countries are combined to create the "trade" variable. Following Bussiere et al. (2009), the real effective exchange rate (which is the average of the bilateral real exchange rates between the country's currency and other major currencies) is used instead of the bilateral exchange rate in terms of US dollars. This helps mitigate volatility in the exchange rate due to any sudden change in bilateral relations among countries and is often a more accurate measure of external competitiveness.

These data were collected from the IMF's International Financial Statistics (IFS) dataset. GDP growth, SIRT, and CPI data were collected from Oxford Economics. If the data were not available in the seasonally adjusted form, they were adjusted using the census X-12 method.

Table 1 shows the mean value of the endogenous variables for each country. Within the sample time period considered, Hungary has the highest average growth rate, followed by Slovakia and Poland. In spite of having a low average growth rate (it is one of two countries with an average growth rate lower than 3\%), the Czech Republic has the highest average trade with other CEE-Baltic countries. Slovakia, although not one of the largest countries in the sample in terms of GDP, has the third highest average trade with other CEE-Baltic countries. This demonstrates the unique nature of Slovakia and explains some other results found in the following sections. The average SIRT varies across countries, from $7.98 \%$ in Romania to $1.57 \%$

3) See, for example, Bettendorf (2017), Pentecote and Rondeau (2015), and Backus et al. (1992). 
in the Czech Republic.

Table 1. Mean of domestic variables

\begin{tabular}{cccccc}
\hline & Growth & Trade & REER & SIRT & CPI \\
\hline BULGARIA & 3,47 & 1790,93 & 95,29 & 2,55 & 5772,37 \\
CROATIA & 3,77 & 1511,94 & 96,38 & 6,05 & 91,31 \\
CZECH & 2,88 & 12106,09 & 91,91 & 1,57 & 91,78 \\
ESTONIA & 3,26 & 985,24 & 99,33 & 2,12 & 98,04 \\
HUNGARY & 5,42 & 8600,02 & 94,80 & 5,82 & 125,58 \\
LATVIA & 3,44 & 1131,29 & 95,60 & & 94,32 \\
POLAND & 3,88 & 10121,47 & 95,80 & 3,87 & 113,70 \\
ROMANIA & 3,87 & 4815,34 & 97,82 & 7,98 & 95,49 \\
SLOVAKIA & 4,09 & 9933,72 & 92,54 & 2,03 & 148,99 \\
SLOVENIA & 2,06 & 2727,24 & 99,05 & 2,12 & 97,90 \\
\hline
\end{tabular}

\section{B. Statistical properties and specifications of the VARX model}

I started by checking the stationarity and co-integration of the data. Stationarity was checked with respect to all the country-specific domestic variables and their corresponding foreign variables. In addition to the commonly used augmented Dickey-Fuller (ADF) test, the weighted-symmetric Dickey-Fuller (WS) test suggested by Park and Fuller (1995) was also used for this purpose.4) Lag length was selected according to the SB criterion. Unit root tests were conducted with variables in levels, first differences, and second differences (if necessary). When the variables are in levels, an intercept and a time trend are included, whereas when in first or second differences, only an intercept is included. The results for the level data for domestic variables are shown in Table 2. The numbers express the t-values at a 5\% significance level. As expected, there is a mix of stationary and nonstationary data across countries, but most of the data fall in the latter category. All the nonstationary data are integrated of order one.

The next step is to define the country-specific VARX models. The GVAR model has the flexibility of handling different specifications for different countries (i.e., the number of domestic and foreign variables goes into each country-specific model). However, because the countries in the sample all have trading relations and are all expected to affect each other, each individual country model initially included all five variables as both domestic and foreign variables 5 ) (constructed using the weight matrix mentioned in the previous section). Next, the order of

4) The WS test exploits the time reversibility of stationary auto-regressive processes in order to increase their power performance. Several authors such as Leybourne et al. (2005) and Pantula et al. (1994) showed evidence of the superior performance of the WS test compared with the ADF test.

5) Several robustness checks were conducted by leaving out some variables as foreign variables for countries that are less integrated with other countries in terms of trade. However, this does not change the main findings of the paper. 
the country-specific VARX $\left(p_{i}, q_{i}\right)$ model was selected using the SB criterion. While selecting the lag order, $p_{i}$ and $q_{i}$ were not allowed to go over 2 because of the small sample size compared with the large number of parameters to be estimated. The selected order of the VARX model through the $\mathrm{SB}$ criterion is shown in Table 3.

Table 2. Unit root tests

\begin{tabular}{cccccccccccc}
\hline Variable & \multicolumn{2}{c}{ Growth } & \multicolumn{2}{c}{ Trade } & \multicolumn{2}{c}{ REER } & \multicolumn{2}{c}{ SIRT } & \multicolumn{2}{c}{ CPI } \\
\hline Statistic & ADF & WS & ADF & WS & ADF & WS & ADF & WS & ADF & WS \\
Critical value & $-3,45$ & $-3,24$ & $-3,45$ & $-3,24$ & $-3,45$ & $-3,24$ & $-3,45$ & $-3,24$ & $-3,45$ & $-3,24$ \\
Bulgaria & $-1,71$ & $-2,10$ & $-3,25$ & $-3,46$ & $-1,46$ & $-1,47$ & $-2,36$ & $-1,95$ & $-1,09$ & $-1,41$ \\
Croatia & $-1,17$ & $-1,63$ & $-2,62$ & $-3,09$ & $-2,40$ & $-1,84$ & $-1,19$ & $-1,44$ & $-1,71$ & $-2,17$ \\
Czech Rep. & $-3,24$ & $-3,47$ & $-3,11$ & $-3,10$ & $-1,79$ & $-1,49$ & $-2,59$ & $-2,60$ & $-1,69$ & $-1,94$ \\
Estonia & $-2,50$ & $-2,75$ & $-2,95$ & $-3,00$ & $-2,05$ & $-2,29$ & $-2,13$ & $-2,30$ & $-1,38$ & $-1,73$ \\
Hungary & $-1,96$ & $-2,04$ & $-3,04$ & $-3,06$ & $-2,58$ & $-1,91$ & $-1,86$ & $-2,06$ & $-1,39$ & $-1,85$ \\
Latvia & $-2,70$ & $-3,03$ & $-3,10$ & $-3,25$ & $-1,48$ & $-1,77$ & & & $-2,31$ & $-2,40$ \\
Poland & $-3,38$ & $-2,91$ & $-3,32$ & $-3,27$ & $-2,70$ & $-2,25$ & $-3,59$ & $-3,79$ & $-2,77$ & $-3,08$ \\
Romania & $-2,77$ & $-3,03$ & $-3,35$ & $-3,58$ & $-2,76$ & $-1,64$ & $-3,65$ & $-3,40$ & $-0,74$ & $-0,54$ \\
Slovakia & $-3,81$ & $-4,12$ & $-2,52$ & $-2,62$ & $-1,06$ & $-0,50$ & $-3,47$ & $-3,35$ & $-2,04$ & $-1,51$ \\
Slovenia & $-3,21$ & $-3,46$ & $-3,29$ & $-3,26$ & $-2,15$ & $-2,28$ & $-3,24$ & $-2,84$ & $-1,72$ & $-2,01$ \\
\hline
\end{tabular}

(Note) Augmented Dickey-Fuller (ADF) and weighted-symmetric Dickey-Fuller (WS) test results. Variables are in levels with an intercept and a time trend.

Table 3. Order of the VARX models and number of co-integrating relations

\begin{tabular}{cccc}
\hline & $p_{i}$ & $q_{i}$ & Co-integrating relations \\
\hline Bulgaria & 2 & 1 & 3 \\
Croatia & 2 & 1 & 3 \\
Czech Rep. & 2 & 1 & 1 \\
Estonia & 1 & 1 & 3 \\
Hungary & 2 & 1 & 2 \\
Latvia & 2 & 1 & 2 \\
Poland & 2 & 1 & 3 \\
Romania & 2 & 1 & 2 \\
Slovakia & 2 & 1 & 3 \\
Slovenia & 2 & 1 & 3 \\
\hline
\end{tabular}

As can be seen in most of the countries, a VARX $(2,1)$ model was selected. The only exception was Estonia, for which a VARX $(1,1)$ model was selected. Given that a number of the variables are nonstationary, Johansen's co-integration test was conducted next to determine the number of co-integrating relations for each country. Here, the specifications consider case IV according to Pesaran et al. (2000), where a linear deterministic trend is implicitly allowed 
for the co-integration space but can be eliminated in the dynamic part of the VEC models. The number of co-integration relations for each country based on the trace statistics is also shown in Table 3. Most countries seem to have either two or three co-integrating relations, except for the Czech Republic, which has one co-integrating relation. Next, individual country-specific VECMX models were estimated subject to the reduced rank restrictions to derive the corresponding error correcting terms. These Error Correction Models (ECMs) were subsequently used to conduct the weak exogeneity test.

\section{Weak exogeneity test}

As mentioned earlier, one of the main assumptions of the GVAR model is the weak exogeneity of country-specific foreign variables, $y_{i, t}^{*}$. In general, a variable in a VARX model is considered to be weakly exogenous if it is not dependent on the contemporaneous values of the endogenous variables, but is likely to depend on the lagged values of these endogenous variables. More formally, $y_{i, t}^{*}$ is considered to be weakly exogenous if $y_{i, t}$ does not affect $y_{i, t}^{*}$ in the long run but $y_{i, t}^{*}$ is said to be "long-run forcing" for $y_{i, t}$. The weak exogeneity test is described in the Appendix.

The results of the test are shown in Table 4. As is evident, all the variables pass the weak exogeneity test, because the assumption of exogeneity cannot be rejected at the $5 \%$ significance level. This is a very desirable result because it confirms the suitability of using a GVAR model for this region.

Table 4. Weak exogeneity test

\begin{tabular}{cccccccc}
\hline Country & F-test & Fcrit-0.05 & Growth & Trade & REER & SIRT & CPI \\
\hline Bulgaria & $\mathrm{F}(3,37)$ & 2,85 & 2,01 & 1,74 & 0,61 & 0,72 & 0,12 \\
Croatia & $\mathrm{F}(4,36)$ & 2,63 & 0,17 & 0,73 & 0,44 & 0,47 & 0,50 \\
Czech Rep. & $\mathrm{F}(4,36)$ & 2,63 & 0,56 & 0,45 & 1,08 & 0,19 & 0,11 \\
Estonia & $\mathrm{F}(3,37)$ & 2,85 & 1,01 & 0,57 & 0,67 & 1,36 & 0,30 \\
Hungary & $\mathrm{F}(3,37)$ & 2,85 & 1,33 & 0,36 & 0,50 & 0,68 & 0,63 \\
Latvia & $\mathrm{F}(2,40)$ & 3,23 & 2,07 & 2,31 & 0,71 & 0,03 & 0,96 \\
Poland & $\mathrm{F}(3,37)$ & 2,85 & 0,49 & 0,33 & 1,74 & 0,47 & 0,56 \\
Romania & $\mathrm{F}(2,38)$ & 3,24 & 0,80 & 0,95 & 0,44 & 2,26 & 2,27 \\
Slovakia & $\mathrm{F}(3,37)$ & 2,85 & 0,18 & 0,29 & 0,59 & 0,87 & 0,38 \\
Slovenia & $\mathrm{F}(2,38)$ & 3,24 & 0,35 & 1,30 & 1,41 & 0,98 & 0,49 \\
\hline
\end{tabular}

(Note) Test results with corresponding degrees of freedom (second column) and 95\% critical values (third column). 


\section{Persistence profiles and stability}

Another important condition for the GVAR system to work properly is the convergence of its persistence profiles. Persistence profiles (PPs) refer to the time profiles of the effects of the system or variable-specific shocks on the co-integrating relations in the GVAR model (Pesaran and Shin 1996). PPs provide important information about the long-run properties of the GVAR system and about the speed with which the co-integrating relations revert to their equilibrium states. PPs should converge to zero in the long term, implying that the system will return to its long-run equilibrium after a system-wide shock. The PPs of this model satisfy this condition. More about PPs are explained in the Appendix.

The stability of the GVAR model can also be determined from the eigenvalues and corresponding moduli, which characterize the dynamic properties of the model. These values should lie inside, and at most on, the unit circle for the model to be stable. The results presented in Table A1 of the Appendix show that the modulus of every eigenvalue of the GVAR is on or within the unit circle. This proves that the model under consideration is stable.

\section{Initial Findings and Dynamic Analysis}

This section discusses the time-varying trade weights, the contemporaneous effects, and the dynamic analysis.

\section{A. Time-varying trade weights}

As mentioned in Section 2, trade weights are calculated for each country to create the country-specific foreign variables. These trade weights reflect the proportion of a country's trade with other countries in the sample. For example, for country $\mathrm{X}$, more trade with country Y leads to a higher weight of country Y in country X's model. Yearly bilateral trade flow data for each of the countries were used to create these weights. The use of time-varying trade weights (instead of fixed trade weights) in this GVAR model means that there are trade weights for each country for every year in the sample. This large trade weight matrix gives insight on how trade flow fluctuated between the countries over the years. For each country in Figure 1, the graphs demonstrate how they were linked with the rest of the countries in terms of trade during the sample period (2003-2017). The sum of weights of every country in every year is equal to 1 . 
Figure 1. Time-varying trade weights

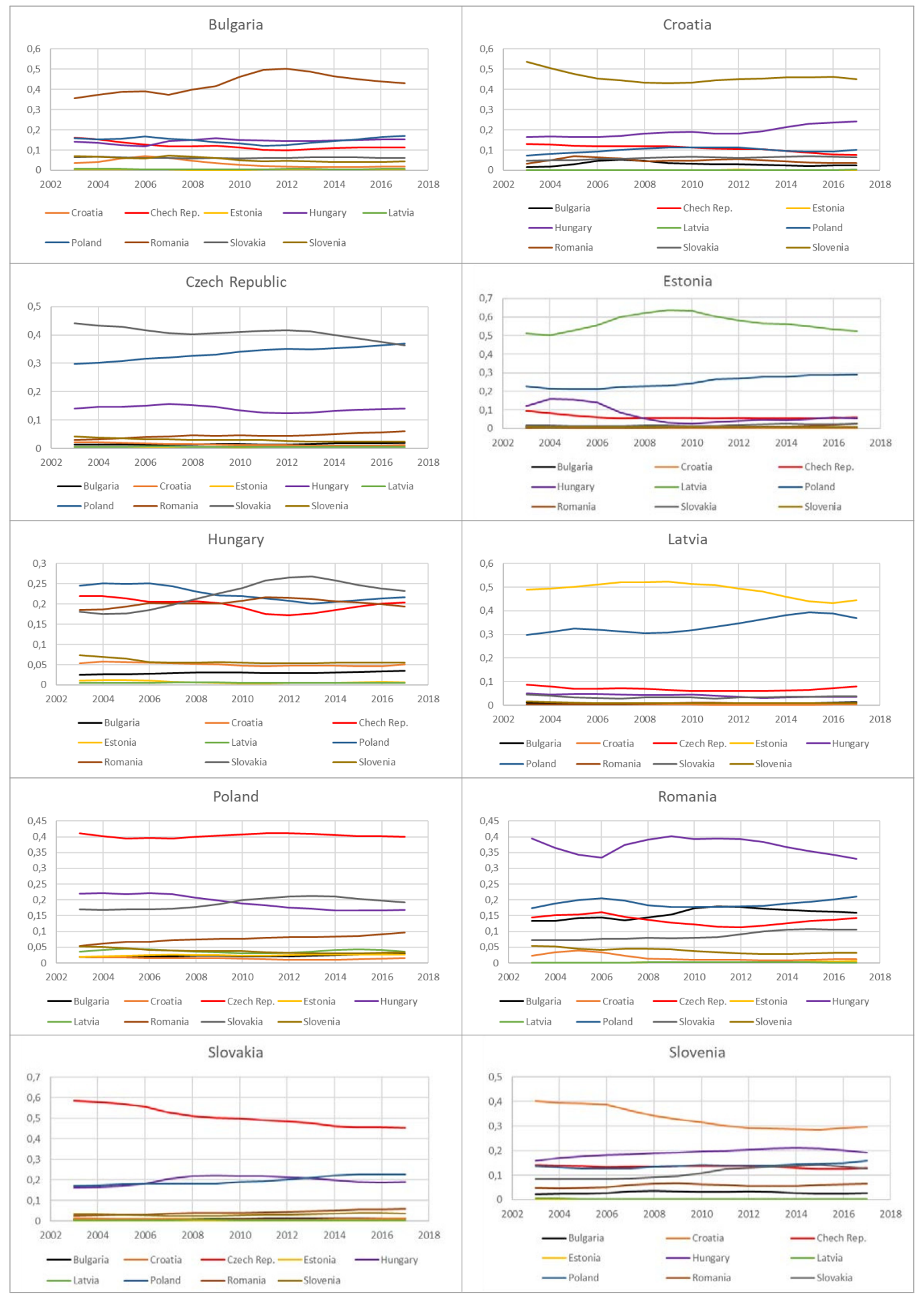


As illustrated in Figure 1, Romania was the most important trading partner for Bulgaria among all the CEE-Baltic countries in the sample. The weight of Romania for Bulgaria is approximately between 0.4 and 0.5 ; for the rest of the countries, it is below 0.2. Croatia and Slovenia remain the countries with the highest trade weight for each other, reflecting the strong trading ties between them throughout the sample period. For the Czech Republic, the two most important countries were Slovakia and Poland. Slovakia was its primary trading partner during most of the sample period, but the importance of Poland has increased steadily over recent years. Apart from these two countries and Hungary, the trade weights of the rest of the countries for the Czech Republic are very low. The two Baltic countries in the sample, Estonia and Latvia, were the major trading partners for each other throughout the sample period. Poland was also an important trading partner for these two countries. The trade relations of Hungary are stronger with four countries (Poland, the Czech Republic, Slovakia, and Romania) compared with those of the other CEE-Baltic countries, and their weights fluctuated between 0.15 and 0.25 over the sample period. For Poland and Slovakia, the country with the highest trade weight was the Czech Republic. Finally, for Romania, the most important country concerning trade was Hungary. In general, no single country dominated trade with all the other countries. All the countries have trading relations with each other, although the main trading partner varies for different countries. The relatively flat lines in the figure indicate that the trade weights for the countries did not fluctuate much during the sample period.

\section{B. Contemporaneous effects}

Contemporaneous effects show how the variables of each country are affected contemporaneously by the combined effect of the same variables of the rest of the countries. These results are presented in Table 5. The values of the coefficients show the domestic country variables' responses to a $1 \%$ change in their foreign counterparts. For example, in Bulgaria, a $1 \%$ increase in growth in the rest of the countries (foreign growth variable) brings a $0.44 \%$ increase in growth in the domestic economy. These results can also be interpreted as impact elasticity and give a good indication of how interconnected the countries are.

In Table 5, the coefficients are also presented with their corresponding Newey-West heteroskedasticity and autocorrelation consistent t-ratios. The values in bold indicate that they are statistically significant at the $5 \%$ level. The results show that, as far as growth and trade are concerned, there is a high degree of contemporaneous co-movement among the countries.

Growth is statistically significant for all the countries in the sample, except for Poland. For Slovakia, the impact elasticity of growth is more than 1 , which indicates that a $1 \%$ growth in the rest of the countries brings a growth of more than $1 \%$ in the same quarter for Slovakia. Trade is also highly statistically significant for all the countries. Slovakia once again shows 
the highest sensitivity to trade with an impact elasticity of more than 1 . The statistically significant coefficients also indicate that these countries are more vulnerable to negative foreign shocks. The impact elasticity of REER, SIRT, and CPI is statistically significant for four, five, and four countries, respectively. Overall, these numbers indicate strong interconnections among the CEE-Baltic countries.

Table 5. Contemporaneous effects

\begin{tabular}{|c|c|c|c|c|c|c|}
\hline & & Growth & Trade & REER & SIRT & CPI \\
\hline \multirow[t]{2}{*}{ Bulgaria } & Coefficient & 0,44 & 0,36 & $-0,014$ & 0,17 & 0,84 \\
\hline & $t$-ratio Newey-West & 2.51 & 14,92 & $-0,15$ & $\mathbf{5 , 5 2}$ & 7,14 \\
\hline \multirow[t]{2}{*}{ Croatia } & Coefficient & 0,65 & 0,17 & 0,20 & $-0,02$ & 0,001 \\
\hline & $t$-ratio Newey-West & 5,25 & 4,25 & 1,84 & $-0,14$ & 0,36 \\
\hline \multirow[t]{2}{*}{ Czech Rep. } & Coefficient & 0,56 & 1,14 & 0,61 & 0,47 & 0,05 \\
\hline & $t$-ratio Newey-West & 7,41 & 14,38 & 2,96 & $\mathbf{3 , 7 0}$ & 1,14 \\
\hline \multirow[t]{2}{*}{ Estonia } & Coefficient & 0,38 & 0,25 & 0,63 & 0,06 & 0,09 \\
\hline & $t$-ratio Newey-West & $3, \mathbf{8 3}$ & 12,92 & 3,92 & 0,66 & 3,62 \\
\hline \multirow[t]{2}{*}{ Hungary } & Coefficient & 0,67 & 0,92 & 1,36 & 1,06 & 0,10 \\
\hline & $t$-ratio Newey-West & 2,51 & 16,67 & 4,07 & $\mathbf{9 , 5 1}$ & 3,31 \\
\hline \multirow[t]{2}{*}{ Latvia } & oefficient & 0,33 & 0,24 & $-0,19$ & & 0,054 \\
\hline & $t$-ratio Newey-West & 2,37 & 9,74 & $-0,73$ & & 1,55 \\
\hline \multirow[t]{2}{*}{ Poland } & Coefficient & 0,03 & 0,82 & 1,27 & 0,40 & 0,02 \\
\hline & $t$-ratio Newey-West & 0,25 & 13,11 & 4,67 & 3,28 & 1,10 \\
\hline \multirow[t]{2}{*}{ Romania } & Coefficient & 0,37 & 0,51 & 0,14 & 2,73 & 0,013 \\
\hline & $t$-ratio Newey-West & 2,44 & 6,44 & 0,91 & 11,10 & 2,32 \\
\hline \multirow[t]{2}{*}{ Slovakia } & Coefficient & 1,57 & 1,29 & 0,17 & 0,29 & 0,20 \\
\hline & $t$-ratio Newey-West & 2,69 & 24,97 & 1,62 & 2,03 & 4,7 \\
\hline \multirow[t]{2}{*}{ Slovenia } & Coefficient & 0,33 & 0,28 & $-0,17$ & 0,01 & $-0,006$ \\
\hline & $t$-ratio Newey-West & 4,27 & 14,38 & $-1,58$ & 0,092 & $-0,90$ \\
\hline
\end{tabular}

(Note) Statistically significant values at the $5 \%$ level are in bold.

\section{Dynamic analysis}

Although they give some initial information, impact elasticities do not say anything about the dynamic interlinkages between the macroeconomic variables of different countries. This section discusses the dynamic analysis by means of the GIRFs originally proposed by Koop et al. (1996) and further developed by Pesaran and Shin (1998). The orthogonalized impulse response functions generally used in traditional VAR analysis require a certain ordering of variables to achieve identification. This approach is not suitable for GVAR models because they require the ordering of not only the variables but also the countries. Furthermore, economic theory and empirical findings provide very little evidence to justify such simultaneous ordering 
for such a large number of countries. The identification of shocks in the GVAR model is further complicated because of the cross-country interactions and high dimensionality of the model. The advantage of GIRFs is that they are invariant to the ordering of countries and variables. This is very convenient for models such as GVAR that involve several countries and variables. Although this makes the economic interpretation of shocks difficult, it is less of a problem if cross-country residuals are not strong. Table A1 shows the average pairwise cross-country correlation of residuals. The values indicate very low residual correlations, and most of them have absolute values of less than 0.1. These results suggest that individual shocks are not much affected by other shocks in this particular GVAR model.

The main aim of this paper is to determine how a positive trade shock in different CEE-Baltic countries affects the growth and inflation of other CEE-Baltic countries. ${ }^{6}$ ) These effects are depicted in Figures 2 and 3, respectively. The GIRFs in Figure 2 show the reaction of growth of each CEE-Baltic country due to a one standard deviation (SD) positive shock to trade in all the countries. The reaction of growth is depicted for up to 20 quarters. For each impulse response, the associated $90 \%$ bootstrap confidence bands 7 ) are also computed. They provide important information regarding the statistical significance of the impulse responses. However, these confidence bands are not reported in the figures for the sake of clarity. ${ }^{8}$ ) For Figure 3 , the confidence bands in almost all the cases suggested that the impulse responses were significant for only a short period (four to five quarters).

The results in Figure 2 show the relative importance of different countries in affecting the growth of other countries through trade. The most important finding is that a trade shock in different CEE-Baltic countries positively affects the growth of other CEE-Baltic countries significantly. The magnitude of the effect is, however, different for each country.

For example, from Figure 2, it is evident that the trade shocks emanating from Slovakia, Poland, and the Czech Republic have the highest impact on the growth of other countries. However, trade shocks in countries such as Bulgaria, Croatia, Estonia, Latvia, and Slovenia have very little spillover effects on the growth of other countries. Clearly, the size of the economy matters in this case. Being the two largest economies in the sample, it was expected that Poland and the Czech Republic would have larger spillover effects as compared to other countries. In terms of GDP, the Bulgarian and Croatian economy sizes equaled almost one-tenth of the largest economy in the sample, Poland. The Estonian, Latvian, and Slovenian economies were even smaller. The time-varying trade weights in Figure 1 also show that the trade weights

6) The reactions to a shock to CPI for different countries were also investigated. However, the results were insignificant for most of the countries.

7) Computed on the basis of 1000 replications.

8) All the figures with confidence bands are available on request. The reactions of other variables (i.e., REER, SIRT, and Trade) to a trade shock are also available on request. They, however, do not provide any important information on the transmission process of the shocks. 
Figure 2. Generalized impulse response functions (GIRFs) of growth after an expansionary 1 SD shock to trade in all the CEE-Baltic countries.
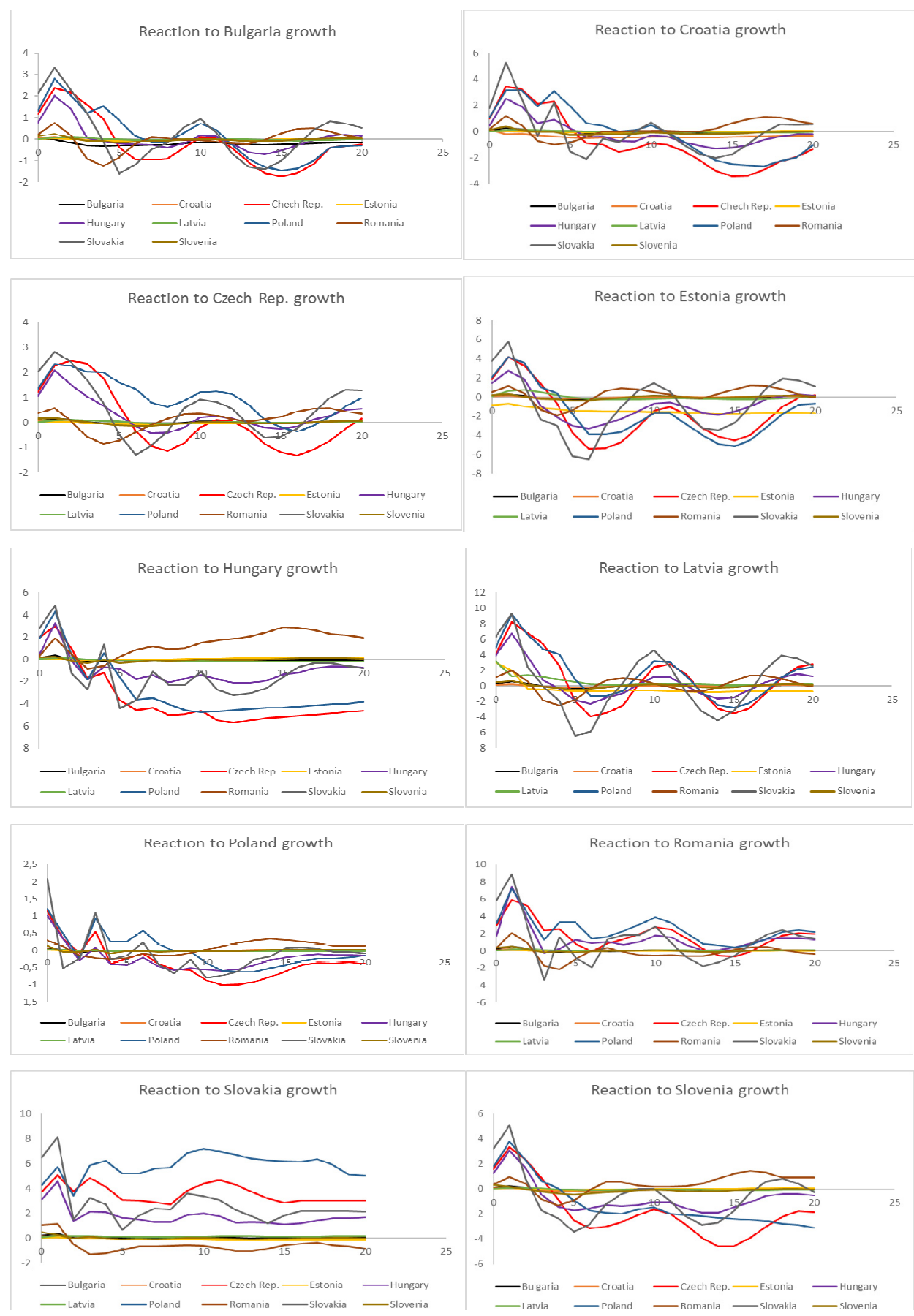

(Note) The graphs show bootstrap median estimates where the forecast horizon extends up to 20 quarters and is recorded along the horizontal axis. The associated $90 \%$ bootstrap confidence bands computed on the basis of 1000 replications of the GIRFs are not shown for the sake of clarity, but are available on request. 
56 Journal of Economic Integration Vol. 35, No. 1

Figure 3. Generalized impulse response functions (GIRFs) of CPI after an expansionary 1 SD shock to trade in all the CEE-Baltic countries.

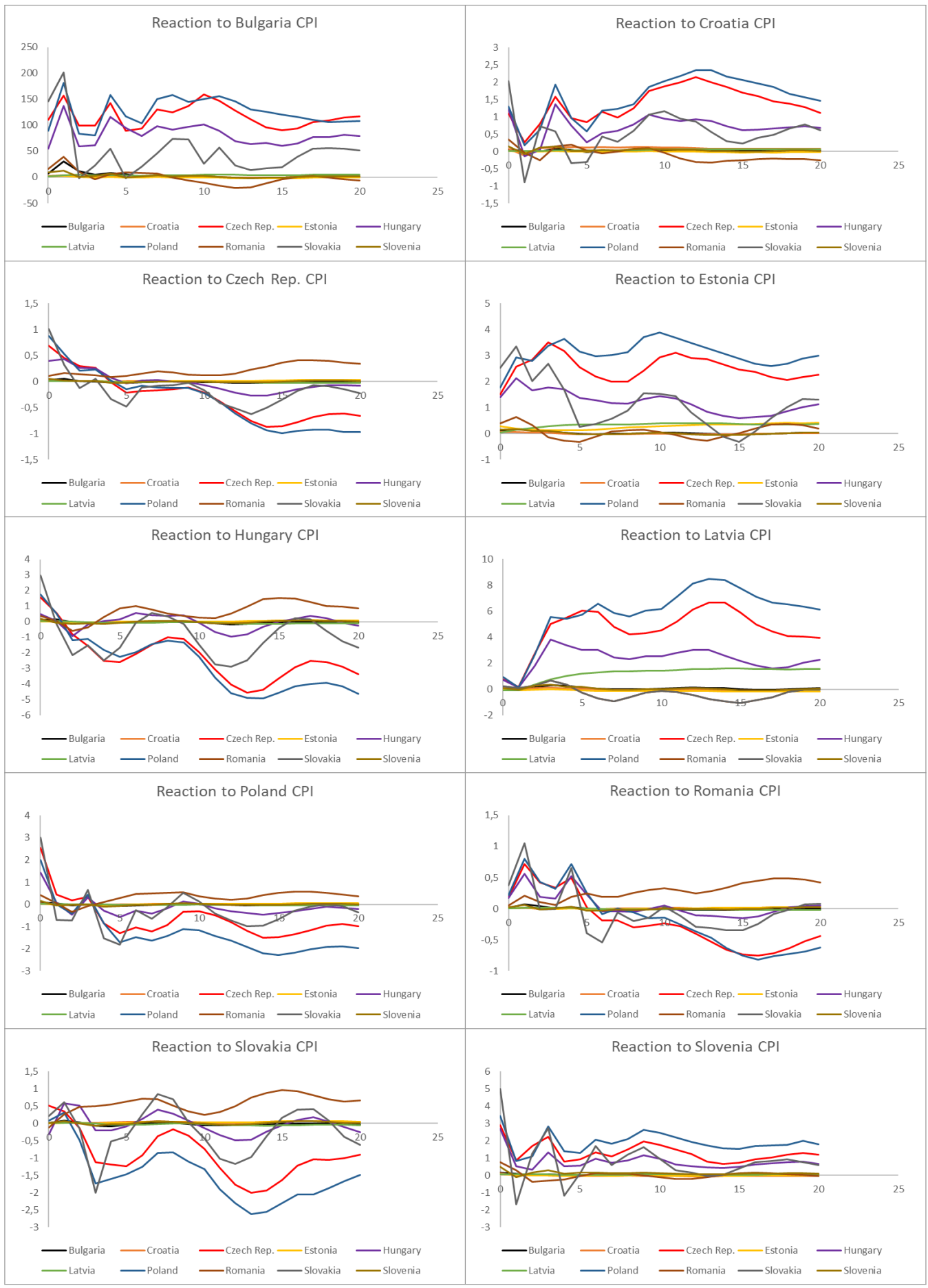

(Note) See Figure 2 
of these countries were significantly smaller than those of other countries, thus reducing their ability to influence the growth of other countries through trade. What is rather striking in the figure is the impact of Slovakian trade on the growth of the rest of the countries.

During the sample time period (2003 2007) considered in this study, most Eastern European countries tried to adapt to the EU trade regimes, and therefore their economies became more open. Slovakia, however, exceeded other East European countries in this transmission process by a good margin. Today, on the basis of different estimations, Slovakia has become one of the most open economies in the EU. According to the World Bank's world development indicator, Slovakia was the world's fifth most open economy in 2018. Trade has fueled its tremendous growth in recent times. According to Eurostat, during the period between 2005 and 2011, the Slovakian GDP increased by about 38.3\%, which is the highest rate of all the EU countries. A recent study by Cetin and Ackrill (2018) found a strong causality from trade to growth for Slovakia. Because of its fast growth, it was referred to as the "Tatra Tiger." The findings of this paper show that an increase in trade in Slovakia not only positively affects the growth in Slovakia but also supports the growth in other CEE-Baltic countries. This is in line with the findings of Iyke (2017), who observed that trade openness is an important factor in the economic growth of CEE countries. Figure 2 also shows that Slovakia is the only exception among all the CEE-Baltic countries to have a permanent growth increase due to a positive trade shock in another CEE-Baltic ${ }^{9}$ ) country. This shows how different Slovakia is from the other countries in the sample and the importance of trade in its growth process.

Although it is surprising how a small economy like that of Slovakia can affect the growth of other countries, the subdued impact of the largest economy in the sample, Poland, should also be noted. Poland is by far the largest economy among all the CEE-Baltic countries considered in this paper. It is more than double the economy of the Czech Republic (the second largest economy) and more than five times that of Slovakia. Nonetheless, the spillover effects of trade shocks from Poland, although positive and significant, are not as large as one would expect. This is perhaps because Poland is still one of the less open economies among the CEE countries. There are recent studies which indicate that Poland's growth is affected more by internal factors. Piatkowski (2013) argued that the adaptation of Western institutions and social norms helped Poland establish the rule of law, robust competition, a free press, and a robust democracy more successfully than any other Eastern European nation. As a result, it has an improved business climate and a rapidly growing domestic market. Improved quality and quantity of education helped foster better human capital. Owing to its weaker external links, it was also one of the least affected countries during the financial crisis of 2007 2008.

Figure 3 sheds some light on the effects of trade shocks on the inflation of CEE-Baltic countries. The GIRFs in each subplot in the figure demonstrate how the CPI of one country

9) All the other countries have short-term effects. 
reacts to a positive shock in trade of all the CEE-Baltic countries in the sample. It can be seen from the figure that mostly trade shocks in Poland, Slovakia, the Czech Republic, and Hungary have some positive spillover effect on the inflation of the rest of the countries. Trade shocks from these countries have a more permanent effect on CPI for Bulgaria, Croatia, Estonia, and Latvia. For the rest of the countries, the effects are short-lived. Trade shocks in Bulgaria, Croatia, Estonia, Latvia, Romania, and Slovenia do not have any significant effect on the inflation of other CEE-Baltic countries.

\section{Robustness Check}

This section re-estimates the results of the baseline model by using structural generalized impulse response functions (SGIRFs), fixed weights, and different country specifications.

\section{A. Using SGIRFs}

The dynamic analysis in GVAR models used in the vast majority of the literature relies strongly on the concept of GIRFs to trace out the dispersions of shocks to macroeconomic variables across countries. In spite of its convenient features, it can be argued that shocks in GIRFs are not orthogonal, and therefore the origins of the shock are difficult to interpret economically. To overcome this problem, SGIRFs are used instead of GIRFs. Under SGIRF analysis, the variables of some countries face recursive ordering so that they are not affected contemporaneously by variables lower in the order for that country or by the variables of other countries. Because Poland is the largest country in the sample based on GDP, it is ordered first in this case. This means that Poland is not affected by changes in the other smaller countries contemporaneously. On the basis of the lower-triangular Cholesky decomposition, the ordering "[Trade, CPI, SIRT, REER, Growth]" is used for Poland. Growth is ordered last because it is the most endogenous variable and is therefore affected contemporaneously by the other variables. ${ }^{10)}$ SGIRF is invariant to the ordering of other countries and variables. Figures 4 and 5 show the response of growth and inflation, respectively, to trade shocks originating in different countries. The impulse response functions are not fundamentally different from the baseline responses found in Figures 2 and 3. The only difference is that the responses are slightly lower in some cases. This might be because Poland, although one of the largest countries in the sample, is not that open as compared to other countries, as discussed in the previous section. As a result, when Poland is prioritized in the model and ordered first, the overall spillover effects become weaker.

10) A different ordering of these variables did not change the outcome significantly. 
Figure 4. Structural generalized impulse response functions (SGIRFs) of growth after an expansionary 1 SD shock to trade in all the CEE-Baltic countries
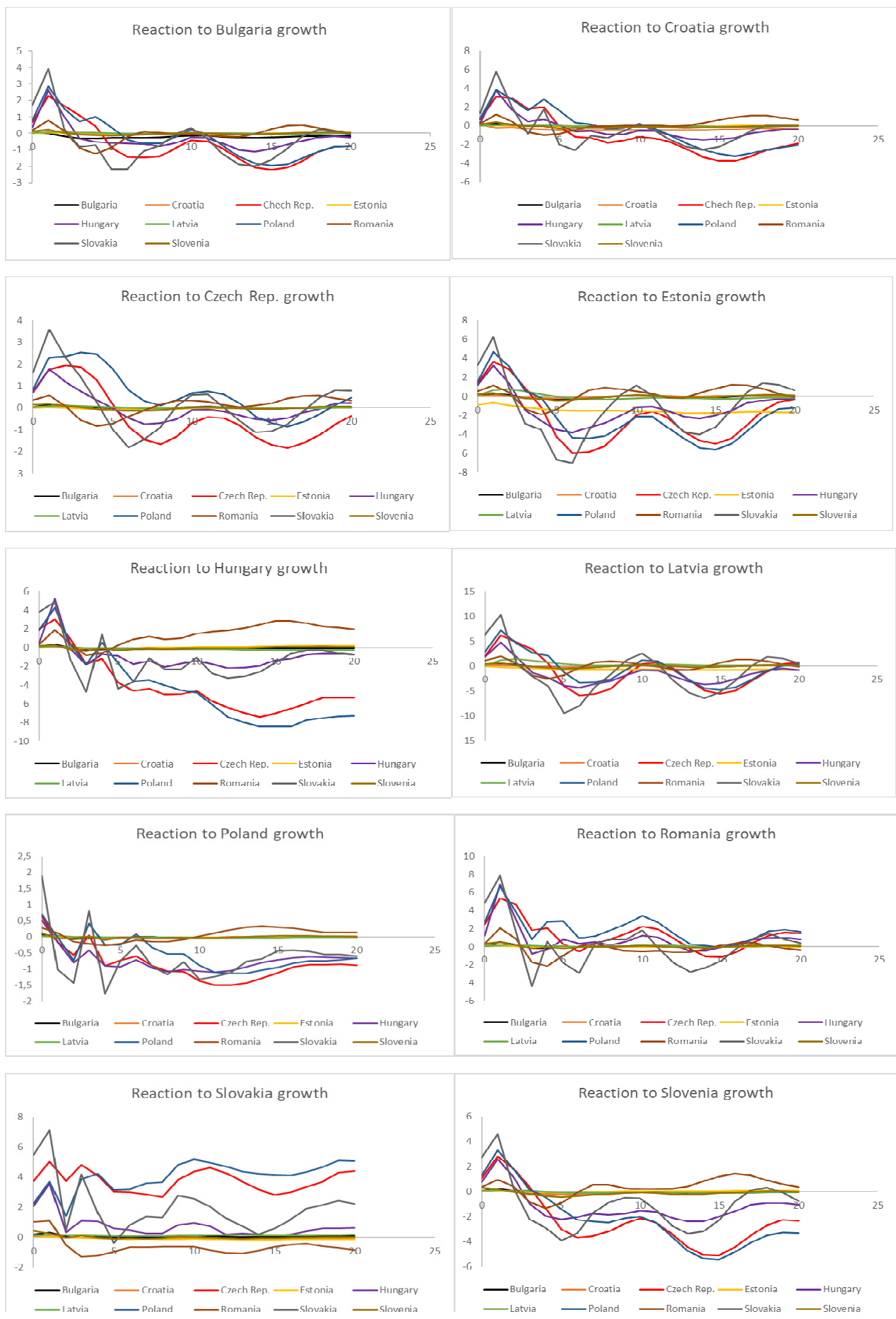

(Note) See Figure 2 
60 Journal of Economic Integration Vol. 35, No. 1

Figure 5. Structural generalized impulse response functions (SGIRFs) of CPI after an expansionary 1 SD shock to trade in all the CEE-Baltic countries

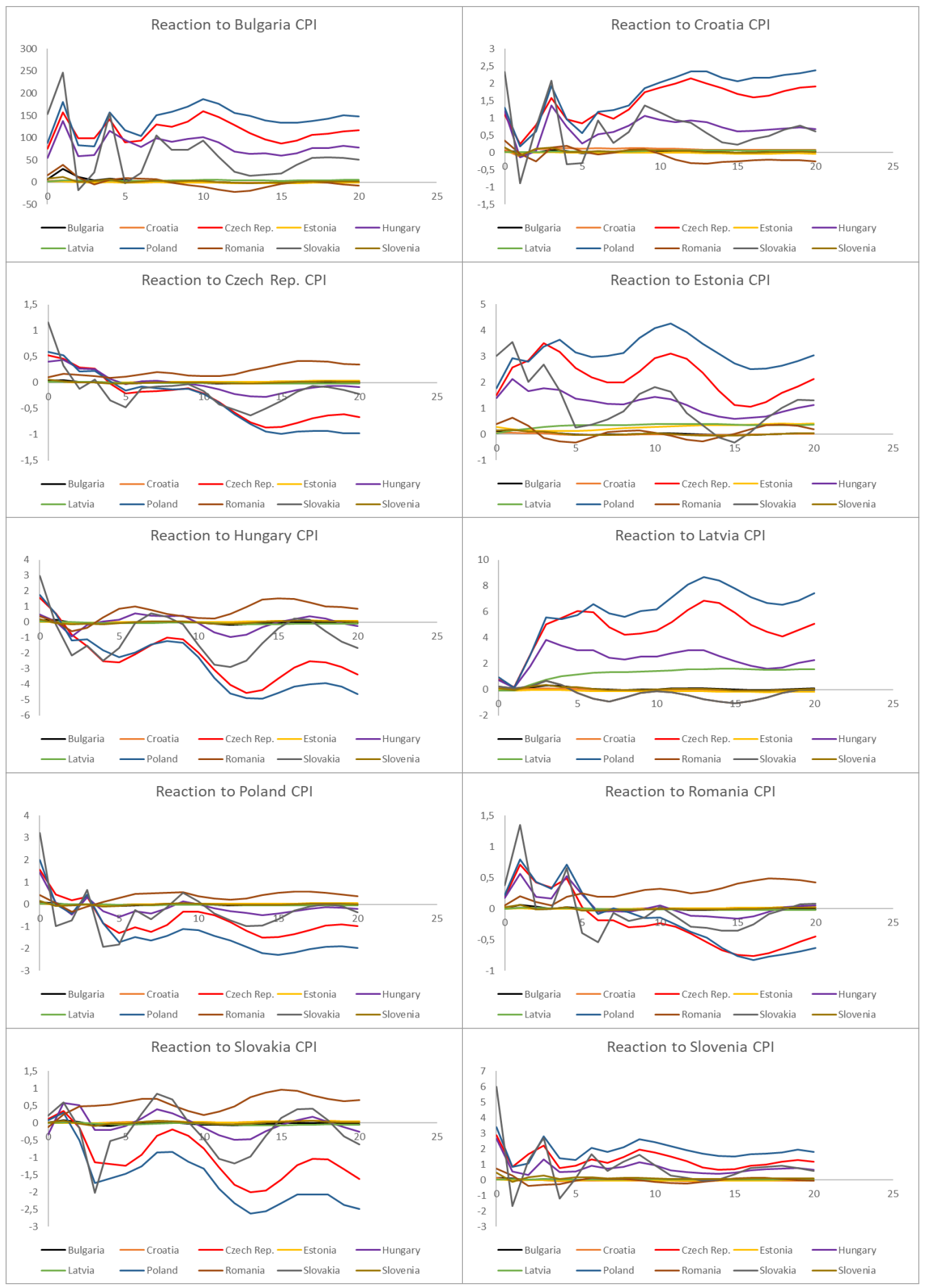

(Note) See Figure 2 


\section{B. Using fixed trade weights and different country specifications}

Two more robustness checks are conducted in this subsection. Firstly, a change in trade weight is considered. The heart of a GVAR model is the weight matrix, computed on the basis of bilateral trade quantities among the countries. This matrix is used to create the foreign variables (which determine the evolution between individual countries and the rest of the countries in the sample) and the link matrix (used to create the global model). The baseline model in this study uses time-varying trade weights instead of commonly used fixed trade weights. However, as Figure 1 suggests, the trade weights among the CEE-Baltic countries did not change significantly for most of the countries during the sample period. Moreover, trade relations between the countries in earlier years might be less relevant as compared to recent times. To account for these arguments, a fixed trade weight is used in this section rather than time-varying trade weights. This weight is computed based on the average trade flows computed for the years from 2012 to 2017.

Secondly, country specification is changed for some of the countries. In the baseline, all the individual country models had all the variables as both domestic and foreign variables. However, some of the countries might be less affected by foreign variables than others. Taking this into account, the individual country models of Poland, the Czech Republic, and Hungary (the three largest economies in the sample) are redefined. For these countries, only growth, trade, and inflation are included in the list of foreign variables under the new specification, leaving out SIRT and REER. For other countries, the specifications are kept the same. In both cases, the impulse response functions did not change significantly from the baseline results, and the major findings remained the same.11)

\section{Concluding Remarks}

The economic integration of CEE-Baltic countries has been a matter of great debate and discussion in recent times. This paper investigates this question by studying the spillover effects of trade on GDP growth and inflation within the 10 CEE-Baltic countries using a GVAR model. The sample period is particularly interesting as it contains both the financial crisis of 2007 2008 and the period during which several CEE-Baltic countries adopted the EU trade regime and the common currency of the euro. Therefore, a time-varying weight was used to capture the volatility of the data during these periods. This weight matrix is used to create the foreign variables for individual countries that provide a connection between the evolution of domestic

11) The impulse response functions for the robustness checks in this subsection are not presented in this paper because they do not vary substantially from the baseline results. However, these results are available on request. 
variables and other countries in the sample. In addition to GDP growth, trade, and inflation, each country's model also includes REER and SIRT as endogenous variables to control for their potential roles in the transmission mechanism.

The results show that the trade spillover effect on economic growth is significant across countries. This is evident from both the contemporaneous effects and the dynamic analysis conducted by means of GIRFs. The results also demonstrate that trade shocks arising from Slovakia, the Czech Republic, and Poland have much larger spillover effects on growth than shocks from other CEE-Baltic countries. This highlights the importance of these countries in the region. However, considering the relative size of their economies, the spillover effects of Slovakian trade shocks are surprisingly higher than those of Poland. Trade shocks in some CEE-Baltic countries (i.e., Poland, Slovakia, the Czech Republic, and Hungary) also have some positive effects on the inflation of other CEE-Baltic countries.

The results of this study have important policy implications. They provide useful insights on the possible effects of the further economic integration of these countries. The results also show that trade plays an important positive role in the growth of these countries. Therefore, further integration is likely to enhance the growth potential of these countries. However, the effects might be different in each country. At the moment, the larger countries in the block, such as Poland and the Czech Republic, are the least affected by foreign trade shocks. These countries need to assess their comparative advantages over other countries and decide whether further integration will result in a positive outcome for them or not. For Slovakia, the country in the sample most sensitive to external trade shocks, further integration may increase its risks during economic downturns in other countries. Slovakia already experienced this after the financial crisis of 2007-2008, when it suffered the most of all the CEE-Baltic countries. This indicates that although things can go well when there are positive shocks emanating from other countries, negative shocks can very quickly change the situation. This can worsen when countries share a currency, as it limits their ability to handle the situation using country-specific tools of monetary policy. Therefore, countries should have a clear understanding of the specific degree of integration that is optimal for them. CEE-Baltic countries should implement their trade policies with these insights in mind.

\section{References}

Andrews, D., and Rees, D. (2009). "Macroeconomic volatility and terms of trade shocks." RBA research discussion paper, rpd 2009-05(Reserve Bank of Australia).

Awokuse, T. (2007). "Causality between exports, imports, and economic growth: Evidence from transition economies." Economic Letters 94, no. 3, 389-395. 
Backus, D., Kehoe, P., and Kydland, F. (1992). "Dynamics of the trade balance and the terms of trade: The S-Curve." NBER Working Paper, 36.

Benkovskis, S., Bessonovs, A., Feldkircher, M., and Wörz, J. (2011). "The transmission of euro area monetary shocks to the Czech Republic, Poland and Hungary: Evidence from a FAVAR model." Focus on European Economic Integration 3, 8-36.

Bettendorf, T. (2017). "Investigating global imbalances: Empirical evidence from a GVAR approach." Economic Modelling 64, 201-210.

Bussière, M., Chudik, A., and Sestieri, G. (2009). "Modelling global trade flows: Results from a GVAR model." ECB Working Paper series, 1087.

Cakir, M., and Kbundi, A. (2013). "Trade shocks from BRIC to South Africa: A Global VAR analysis." Economic Modelling 32, 190-210.

Cetin, R., and Ackrill, R. (2018). "Exports, imports, growth and causality: A study of slovakia." Post-Communist Economies 30, no. 3, 395-404.

Dees, S., Holly, S., Pesaran, M. H., and Smith, L. (2007). "Long run macroeconomic relations in the global economy." Economics - The Open-Access, Open-Assessment E-Journal 1, no. 3, 1-20.

Feldkircher, M. (2015). "A global macro model for emerging Europe." Journal of Comparative Economics 43, 706-726.

Harrison, B., and Moore, W. (2009). "Spillover effects from London and Frankfurt to Central and Eastern European stock markets." Applied Financial Economics 19, no. 18, 1509-1521.

Horvath, R., and Rusnak, M. (2009). "How important are foreign shocks in a small open economy? the case of Slovakia." Global Economy Journal 9, no. 1, 1524-1561.

Hájek, J., and Horváth, R. (2016). "The spillover effect of Euro area on Central and Southeastern european economies: A global var approach.” Open Economies Review 27, no. 2, 359-385.

Iyke, B. (2017). "Does trade openness matter for economic growth in the CEE countries?." Review of Economic Perspectives 17, no. 1, 3-14.

Jimenez-Rodriguez, R., Morales-Zumaquero, A., and Egert, B. (2010). "The VARying effect of foreign shocks in central and Eastern Europe.” William Davidson Institute Working Paper, 989.

Johansen, S. (1992). "Cointegration in partial systems and the efficiency of single-equation analysis." Journal of Econometrics 52, 231-254.

Keppel, C., and Prettner, K. (2015). "How interdependent are Eastern European economies and the Euro area?." The Quarterly Review of Economics and Finance 58, 18-31.

Koop, G., Perasan, H., and Potter, S. (1996). "Impulse response analysis in nonlinear multivariate models." Journal of Econometrics 74, no. 1, 119-147.

Kucharcuková, O. B., Claeys, P., and Vasicek, B. (2016). "Spillover of the ECB's monetary policy outsidethe euro area: How different is conventionalfrom unconventional policy?.” Journal of Policy Modelling 38, 199-225.

Leybourne, S., Kim, T., and Newbold, P. (2005). "Examination of some more powerful modifications of the Dickey-Fuller test." Journal of Time Series Analysis 26, 355-369.

Mann, K. (2015). "The EU, a growth engine? the impact of European integration on economic growth in Central Eastern Europe." FIW Working Paper, 136. 
Máckowiak, B. (2006). "How much of the macroeconomic variation in Eastern Europe is attributable to external shocks?." Comparative Economic Studies 48, no. 3, 523-544.

Nannicini, T., and Billmeier, A. (2011). "Economies in transition: How important is trade openness for growth?." Oxford Bulletin of Economics and Statistics 73, no. 3, 287-314.

Pantula, S. G., Gonzalez-Farias, G., and Fuller, W. A. (1994). "A comparison of unit-root test criteria." Journal of Business \& Economic Statistics 12, 449-459.

Park, H., and Fuller, W. (1995). "Alternative estimators and unit root tests for the autoregressive process." Journal of Time Series Analysis 16, 415-429.

Pentecote, J., and Rondeau, F. (2015). "Trade spillovers on output growth during the 2008 financial crisis." International Economics 143, 36-47.

Pesaran, M. H., Schuermann, T., and Weiner, S. M. (2004). "Modelling regional interdependencies using a global error-correcting macroeconometric model.” Journal of Business \& Economic Statistics 22, 129-162.

Pesaran, M. H., and Shin, Y. (1996). "Cointegration and speed of convergence to equilibrium.” Journal of Econometrics 71, no. 1-2, 117-143.

Pesaran, M. H., and Shin, Y. (1998). "Generalized impulse response analysis in linear multivariate models." Economic Letters 58, no. 1, 17-29.

Pesaran, M. H., Shin, Y., and Smith, R. J. (2000). "Structural analysis of vector error correction models with exogenous i(1) variables." Journal of Econometrics 97, 293-343.

Piatkowski, M. (2013). "Poland's new golden age: Shifting from Europe's periphery to its center." World Bank Policy Research Working Paper Series, 6639.

Serwa, D., and Bohl, M. T. (2005). "Financial contagion vulnerability and resistance: A comparison of European stock markets.” Economic Systems 29, no. 3, 344-362.

Syllignakis, M. N., and Kouretas, G. P. (2011). "Dynamic correlation analysis of financial contagion: Evidence from the Central and Eastern European markets." International Review of Economics and Finance 20, no. 4, 717-732.

Taghizadeh-Hesary, F., and Yoshino, N. (2018). "Assessment of the channels of transmission of oil price fluctuations to the economy." Argumenta Oeconomica 41, no. 2, 5-34.

Taghizadeh-Hesary, F., Yoshino, N., Abadi, M. M. H., and Farboudmanesh, R. (2016). "The response of macro variables of emerging and developed oil importers to oil price movements." Journal of the Asia Pacific Economy 21, no. 1, 91-102.

Taghizadeh-Hesary, F., Yoshino, N., Abdoli, G., and Farzinvash, A. (2013). "An estimation of the impact of oil shocks on crude oil exporting economies and their trade partners." Frontiers of Economics in China 8, no. 4, 571-591.

Wacziarg, R., and Welch, K. H. (2008). "Trade liberalization and growth: New evidence." World Bank Economic Review 22, no. 2, 187-231. 


\section{Appendix 1: Persistence profile (PP)}

As mentioned in Dees et al. (2007), to calculate PPs, consider the GVAR(p) model given by (8). The moving average representation of this model can be written as

$$
\begin{aligned}
y_{t} & =d_{t}+\sum_{s=0}^{\infty} A_{s} \varepsilon_{t-s} \\
& =\varepsilon_{t}+A_{1} \varepsilon_{t-1}+A_{2} \varepsilon_{t-2}+\cdots
\end{aligned}
$$

Here, $d_{t}$ is the deterministic part of $y_{t} . A_{s}$ is derived recursively as

$$
A_{s}=\sum_{s=1}^{\infty} F_{i} A_{s-i}
$$

with $A_{0}=I_{m}, A_{s}=0$ for $s<0$. Using the identity $z_{i, t}=W_{i} y_{t}$, Equation 10 can be written as

$$
z_{i, t}=W_{i} d_{t}+W_{i} A_{0} \varepsilon_{t}+\sum_{s=1}^{\infty} W_{i} A_{s} \varepsilon_{t-s}
$$

In a GVAR context, the variable $\beta_{i}^{\prime} z_{i, t}$ represents the co-integrating relations in terms of the country-specific variables. The $P P \mathrm{~s}$ of $\beta_{i}^{\prime} z_{i, t}$ with respect to a system-wide shock to $\varepsilon_{t}$ are calculated as

$$
P P\left(\beta_{j, i}^{\prime} z_{i, t} ; \varepsilon_{t}, n\right)=\frac{\beta_{j i}^{\prime} W_{i} A_{n} \sum_{\varepsilon} A_{n}^{\prime} W_{i}^{\prime} \beta_{j i}}{\beta_{j i}^{\prime} W_{i} A_{0} \sum_{\varepsilon} A_{0}^{\prime} W_{i}^{\prime} \beta_{j i}}
$$

for $n=0,1,2, \cdots$, where $\beta_{j, i}^{\prime}$ is the $j$ th co-integrating relation in the $i$ th country $\left(j=1,2, \cdots, r_{i}\right)$ and $\Sigma_{\varepsilon}$ is the covariance matrix of $\varepsilon_{t}$. The $A_{n}$ matrices are calculated based on A3.

$P P$ s have a value of unity on impact and should converge to zero in the long term, which implies that the system will return to its long-run equilibrium after a system-wide shock. 


\section{Appendix 2: Weak exogeneity test}

$y_{i, t}^{*}$ is considered to be weakly exogenous if $y_{i, t}$ does not affect $y_{i, t}^{*}$ in the long run, but $y_{i, t}^{*}$ is said to be "long-run forcing" for $y_{i, t}$. As shown in Johansen (1992), this assumption allows proper identification of the co-integration relation. In the formal test, the joint significance of the estimated error correction terms in auxiliary equations for country-specific foreign variables $y_{i, t}^{*}$ is tested. Specifically, for each $l$ th element of $y_{i, t}^{*}$, a regression of the following form is conducted:

$$
\Delta y_{i, t, l}^{*}=a_{i, l}+\sum_{j=1}^{r_{i}} \delta_{i, j, l}^{*} E \widehat{E M_{i, j, t}-1}+\sum_{s=1}^{p_{i}^{*}} \phi_{i, s, l}^{\prime} \Delta y_{i, t-s}+\sum_{s=1}^{q_{i}^{*}} \Psi_{i, s, l} \widehat{\Delta y_{i, t-s}^{*}}+\eta_{i, t, l}
$$

where $E \widehat{E M_{i, j, t}-1}$, for $j=1,2, \cdots, r_{i}$, are the estimated error correction terms corresponding to the $r_{i}$ co-integrating relations found for the $i t h$ country, and $p_{i}^{*}$ and $q_{i}^{*}$ are the orders of the lagged changes for the domestic and foreign variables, respectively. The test for weak exogeneity is an F-test of the joint hypothesis that $\delta_{i, j, l}=0$ for $j=1,2, \cdots, r_{i}$ in the above equation. It is not necessary that lag orders of $p_{i}^{*}$ and $q_{i}^{*}$ are the same for the underlying country-specific model. They are selected using the SB criterion.

Table A1. Average pairwise cross-country correlations of residuals

\begin{tabular}{cccccc}
\hline & Growth & Trade & REER & SIRT & CPI \\
\hline Bulgaria & $--0,00069$ & 0,015232 & 0,137099 & 0,009965 & 0,014513 \\
Croatia & $-0,03489$ & 0,02719 & 0,074662 & $-0,01432$ & 0,119133 \\
Czech Rep. & $-0,03027$ & $-0,22425$ & $-0,09715$ & 0,010677 & 0,09782 \\
Estonia & $-0,03403$ & 0,069058 & 0,098881 & 0,026636 & 0,12637 \\
Hungary & $-0,14743$ & 0,026867 & $-0,13124$ & $-0,03065$ & 0,201407 \\
Latvia & 0,021013 & 0,027385 & 0,070645 & & 0,153713 \\
Poland & $-0,13108$ & $-0,10684$ & $-0,19656$ & 0,000749 & 0,109706 \\
Romania & $-0,03035$ & 0,049822 & $-0,00017$ & $-0,08552$ & $-0,02197$ \\
Slovakia & 0,039486 & $-0,14418$ & 0,057399 & $-0,08663$ & 0,083764 \\
Slovenia & 0,023867 & $-0,00693$ & 0,191204 & 0,019814 & 0,150895 \\
\hline
\end{tabular}


Table A2. Eigenvalues of the GVAR model and their corresponding moduli

\begin{tabular}{|c|c|}
\hline Eigenvalues of the GVARmodel in descending order & Corresponding moduli \\
\hline $1.00000000000000+0.00000000000000 \mathrm{i}$ & 1 \\
\hline $1.00000000000000-0.00000000000000 \mathrm{i}$ & 1 \\
\hline $1.00000000000000+0.00000000000001 \mathrm{i}$ & 1 \\
\hline $1.00000000000000-0.00000000000001 \mathrm{i}$ & 1 \\
\hline $1.00000000000000+0.00000000000002 \mathrm{i}$ & 1 \\
\hline $1.00000000000000-0.00000000000002 \mathrm{i}$ & 1 \\
\hline $1.00000000000000+0.00000000000000 \mathrm{i}$ & 1 \\
\hline $1.00000000000000-0.00000000000000 \mathrm{i}$ & 1 \\
\hline $1.00000000000000+0.00000000000001 \mathrm{i}$ & 1 \\
\hline $1.00000000000000-0.00000000000001 \mathrm{i}$ & 1 \\
\hline $1.00000000000000+0.00000000000000 \mathrm{i}$ & 1 \\
\hline $1.00000000000000-0.00000000000000 \mathrm{i}$ & 1 \\
\hline $0.99999999999998+0.00000000000000 \mathrm{i}$ & 1 \\
\hline $0.99999999999998-0.00000000000000 \mathrm{i}$ & 1 \\
\hline $0.99999999999997+0.00000000000013 i$ & 1 \\
\hline $0.99999999999997-0.00000000000013 \mathrm{i}$ & 1 \\
\hline 0.99999999999966 & 1 \\
\hline $0.91486828435899+0.22439500617632 \mathrm{i}$ & 0,981488 \\
\hline $0.91486828435899-0.22439500617632 \mathrm{i}$ & 0,981488 \\
\hline 0.89659590039514 & 0,941986 \\
\hline 0.83194262465680 & 0,941986 \\
\hline $0.73978312993664+0.64501131599855 \mathrm{i}$ & 0,896596 \\
\hline $0.73978312993664-0.64501131599855 \mathrm{i}$ & 0,831943 \\
\hline $0.71795173925912+0.17736775963987 i$ & 0,743012 \\
\hline $0.71795173925912-0.17736775963987 i$ & 0,743012 \\
\hline 0.70856610189697 & 0,739536 \\
\hline $0.69122049272374+0.16013471728501 \mathrm{i}$ & 0,739536 \\
\hline $0.69122049272374-0.16013471728501 \mathrm{i}$ & 0,709527 \\
\hline $0.61650457265236+0.10782479620448 \mathrm{i}$ & 0,709527 \\
\hline $0.61650457265236-0.10782479620448 \mathrm{i}$ & 0,708566 \\
\hline 0.58115548509788 & 0,698562 \\
\hline $0.57318287892166+0.19187334992204 \mathrm{i}$ & 0,698562 \\
\hline $0.57318287892166-0.19187334992204 \mathrm{i}$ & 0,625863 \\
\hline 0.54198134926321 & 0,625863 \\
\hline $0.50555817324353+0.11692378549589 \mathrm{i}$ & 0,609026 \\
\hline $0.42414414658984+0.55505898544633 i$ & 0,604445 \\
\hline $0.42414414658984-0.55505898544633 \mathrm{i}$ & 0,604445 \\
\hline $0.42015758071502+0.35910024282534 \mathrm{i}$ & 0,599332 \\
\hline $0.42015758071502-0.35910024282534 \mathrm{i}$ & 0,599332 \\
\hline 0.37130717719283 & 0,581155 \\
\hline $0.50555817324353-0.11692378549589 \mathrm{i}$ & 0,609026 \\
\hline $0.36270086968662+0.48924498124704 i$ & 0,561075 \\
\hline $0.36270086968662-0.48924498124704 \mathrm{i}$ & 0,561075 \\
\hline $0.31360987032039+0.33606554036794 \mathrm{i}$ & 0,552707 \\
\hline $0.31360987032039-0.33606554036794 \mathrm{i}$ & 0,552707 \\
\hline $0.29179895644510+0.68331546777732 \mathrm{i}$ & 0,552128 \\
\hline
\end{tabular}


Table A2. Continued

\begin{tabular}{|c|c|}
\hline Eigenvalues of the GVARmodel in descending order & Corresponding moduli \\
\hline $0.29179895644510-0.68331546777732 \mathrm{i}$ & 0,541981 \\
\hline $0.22708141863738+0.02585640904832 \mathrm{i}$ & 0,526668 \\
\hline $0.22708141863738-0.02585640904832 \mathrm{i}$ & 0,526668 \\
\hline $0.20484466089060+0.06763449780574 \mathrm{i}$ & 0,518903 \\
\hline $0.20484466089060-0.06763449780574 \mathrm{i}$ & 0,518903 \\
\hline $0.16395391081509+0.57646981453441 \mathrm{i}$ & 0,486947 \\
\hline $0.16395391081509-0.57646981453441 \mathrm{i}$ & 0,486947 \\
\hline $0.09319398477464+0.17574366809326 \mathrm{i}$ & 0,459664 \\
\hline $0.09319398477464-0.17574366809326 \mathrm{i}$ & 0,459664 \\
\hline 0.09031251998183 & 0,457711 \\
\hline $0.06091647544897+0.00707248134078 \mathrm{i}$ & 0,454681 \\
\hline $0.06091647544897-0.00707248134078 \mathrm{i}$ & 0,454681 \\
\hline 0.04348387113031 & 0,417617 \\
\hline 0.00000000000000 & 0,399811 \\
\hline 0.00000000000000 & 0,399811 \\
\hline 0.00000000000000 & 0,380889 \\
\hline 0.00000000000000 & 0,380889 \\
\hline 0.00000000000000 & 0,371307 \\
\hline$-0.02770338671474+0.52593920502169 \mathrm{i}$ & 0,353436 \\
\hline$-0.02770338671474-0.52593920502169 \mathrm{i}$ & 0,353436 \\
\hline-0.05899876555181 & 0,282538 \\
\hline$-0.07483930345549+0.34542169272758 \mathrm{i}$ & 0,282538 \\
\hline$-0.07483930345549-0.34542169272758 \mathrm{i}$ & 0,240917 \\
\hline-0.08643439087297 & 0,240917 \\
\hline$-0.09074711639840+0.03904829592793 \mathrm{i}$ & 0,228549 \\
\hline$-0.09074711639840-0.03904829592793 i$ & 0,228549 \\
\hline$-0.09455658114210+0.47767828930058 \mathrm{i}$ & 0,215721 \\
\hline$-0.09455658114210-0.47767828930058 \mathrm{i}$ & 0,215721 \\
\hline$-0.11076319958627+0.01735405672888 \mathrm{i}$ & 0,198924 \\
\hline$-0.11076319958627-0.01735405672888 \mathrm{i}$ & 0,198924 \\
\hline$-0.17242334888638+0.53392422998730 \mathrm{i}$ & 0,112114 \\
\hline$-0.17242334888638-0.53392422998730 \mathrm{i}$ & 0,112114 \\
\hline$-0.17994594516934+0.16018834491613 \mathrm{i}$ & 0,098792 \\
\hline$-0.17994594516934-0.16018834491613 i$ & 0,098792 \\
\hline$-0.19913440024137+0.20043304252941 i$ & 0,090313 \\
\hline$-0.19913440024137-0.20043304252941 \mathrm{i}$ & 0,086434 \\
\hline$-0.29010322416928+0.24681289264583 \mathrm{i}$ & 0,061326 \\
\hline$-0.29010322416928 \quad-0.24681289264583 \mathrm{i}$ & 0,061326 \\
\hline$-0.30886984602873+0.25386589265877 \mathrm{i}$ & 0,058999 \\
\hline$-0.30886984602873-0.25386589265877 \mathrm{i}$ & 0,043484 \\
\hline$-0.36754033840986+0.26767320107544 \mathrm{i}$ & 0 \\
\hline$-0.36754033840986-0.26767320107544 i$ & 0 \\
\hline-0.41761728520574 & 0 \\
\hline-0.45771091165602 & 0 \\
\hline-0.55212835692051 & 0 \\
\hline
\end{tabular}

